sometimes eminent ones, into fields of which they are not landlords, nor even tenants, and where they describe the scene, enunciate laws, or give directives on the authority of their absentee reputation instead of the evidence before them. Is it my own prejudice that social scientists are less inclined to this kind of bad manners than basic ones? Probably; for example, the only piece of discussion (of which there must surely have been more than this) that the editors have thought worth including follows a paper by the assistant director for science of the United States Bureau of Narcotics and Dangerous Drugs; their purpose in doing so is perhaps to remind him that the high tension passing through the barbed wire does not respect the direction from which the cow approaches it.

On the other hand, the two "social" authors seem to me to grow in stature by putting their roots down firmly on their side of the fence. Helen Nowlis, cool and wise as ever, emphasizes that there are two separate drug problemsa medical problem and a people problem; that student drug use is a social problem that extends far beyond drugs; and that "to rely on presenting the effects of drugs on the body is not enough".

Dr Bueno, on the other hand, ends his paper "The Problem of Drug Addiction (sic) in Mexico", and indeed the book as a whole: "their lies are so clear to their hearts and senses that I fear they'd rather die than renounce them, if not treated with intelligence, so strongly do they persist in their doctrines and superstitions". One might be pardoned for thinking that he is referring to the current debaters about certain problems of drug dependence; in fact, he is quoting from an early seventeenth century Manual for the Ministers to the Indians. Perhaps we need a twentieth century "Manual for Professors ministering to Each Other". C. R. B. JOYCE

\section{Inside Plants}

Introduction to the Fine Structure of Plant Cells. By Myron C. Ledbetter and Keith R. Porter. Pp. ix +188 (51 Plates). (Springer-Verlag: Berlin and New York, 1970.) 54DM; \$14.80.

LEDBETTER and Porter have produced an outstanding collection of plant electron micrographs. Probably no other laboratory in the world could bring forward a group of such sustained high quality across such a wide range of material. Such atlases, which have now been emerging regularly from various laboratories for about seven years, conveniently chart the progress made in the techniques for the preparation of plant material. That plant techniques have now, in the best laboratories, caught up with animal preparative techniques, can be demonstrated by comparing one of the first atlases (Stephen Hurry's excellent The Microstructure of Cells of 1964) with this production.

The text. however, which is generous compared with most atlases and well referenced, has limitations. The highly critical approach, applied to the quality of the micrographs, has not been applied to the text. Several statements are either wrong or misleading, for example, "Apparently the $S_{3}$ layer has a higher content of matrix substances (pectins, lignins and sporopollenins) ..." (page 61); "The cuticle ... is in turn impregnated with ... waxes and oils, which ... render it resistant as well to insect pests and the invasion of microbial and viral diseases" (page 109); "The large size of mesophyll cells is due in part to their relatively large vacuole" (page 133); "The absence of starch from the plastids reflects only the inability of permanganate to fix it ..." (page 161); ". . . the Ubisch bodies, which are absorbed onto the surfaces of the pollen grains" (page 168).

Other statements may be true, but have no scientific backing to my knowledge, for example ". . . the plasmodesmata provide for the intercellular movements of large and small molecules ..." (page 49); ". . . the Casparian strip assures that entering ions must pass through the plasma membranes of the endodermal protoplasts ..." (page 81); "Cutin .. . Produced by epidermal cells, it moves through their primary walls and floods out over their exposed surfaces . . ." (page 113).

Plate 6.3 is labelled "Collenchyma". It is, however, a filament cell, at best a very atypical form of this type of cell and not representative in a number of ways. The structure of companion cells is given in detail, but no mention is made of the fact that they are absent in all gymnosperms, in a few angiosperms as well, and in all angiosperms in early stages of development. Cutin chemistry is much better understood than is suggested on page 113. Lignin (page 109) is an infrequent component of the epidermal cells of higher plants.

In short, the micrographs of this work and their references may be used as the most up to date and (with regard to the micrographs) the most technically accomplished of their kind available in a collected form. But the text must be treated with great care.

\section{B. E. JUNIPER}

\section{Comfort of Clothes}

Clothing: Comfort and Function. By Lyman Fourt and Norman R. S. Hollies. Pp. ix +254. (Dekker: New York, November 1970.) $\$ 14.50 ; £ 6.90$. THIS book is concerned with the interactions of clothing with the thermal balance between man's metabolic pro- duction of heat and his exchange of heat with the environment. Readers interested in this subject will doubtless be familiar with the classic Physiology of Heat Regulation and the Science of Clothing by L. H. Newburgh (Saunders, Philadelphia and London, 1949). The present book discusses more recent work which has added to basic knowledge of the subject, and includes information derived from studies of the comfort properties of military clothing conducted in government research laboratories in the United States and elsewhere.

The book deals exclusively with the interaction of "normal" clothing as worn by the military and by civilians in everyday life with the transfer of sensible and evaporative heat between man and his environment. It does not deal with special clothing using auxiliary power for heating or cooling inside the clothing (such as space suits) nor with the mechanical properties of clothing (strength, durability and so on).

The first chapter discusses various quantities and units used in clothing comfort studies, and the second considers clothing as a quasiphysiological system, including discussion of the air content of fabrics and clothing systems and the effects of wind and body motion on the thermal balance. The third chapter consists of a discussion of clothing types for different parts of the body.

The next chapter, concerned with heat and moisture relations in clothing, describes test methods involving apparatus and human subjects. The latter aspect of such studies is treated in more detail in the fifth chapter. There is an account of various physical properties of clothing and clothing materials in relation to comfort, including among others air and water permeability, flammability, static electricity and radiant heat characteristics, in the sixth chapter. Next, natural and man-made fibres are compared with respect to the comfort properties of fabrics made from them, and in a short final chapter the authors discuss briefly current trends and developments involving new materials and finishes, new techniques and new concepts of clothing design.

This book is an extensive review of published works with 477 references. For this alone it is valuable and will be useful to people concerned with the comfort of clothing in spite of a few misprints and errors.

\section{W. H. ReES}

\section{The Seas are Changing}

The Sea: Ideas and Observations on Progress in the Study of the Seas. Edited by Arthur E. Maxwell. Vol. 4: New Concepts of Sea Floor Evolution. Part 1: General Observations. Pp. xi+ 791. f15.25. Part 2: Regional Obser- 